\title{
Protective role of berberine and Coptischinensis extract on T2MD rats and associated islet Rin-5f cells
}

\author{
YU-YU JIANG ${ }^{1 *}$, HAN-MING CUI ${ }^{2 *}$, JIA-LONG WANG ${ }^{2}$, HUI LIU $^{3}$, MENG-MENG DANG $^{3}$, \\ QIU-YAN ZHANG ${ }^{2}$, FANG YANG ${ }^{4}$, JIAN-TAO KOU ${ }^{5}$ and XIAO-LIN TONG ${ }^{6}$
}

\begin{abstract}
${ }^{1}$ The Management of Chronic Disease and Rehabilitation Department, Wuxi Medical School, Jiangnan University, Wuxi, Jiangsu 214122; ${ }^{2}$ Department of Chinese Traditional Medicine Research and Development Center, Guang'anmen Hospital,

China Academy of Chinese Medical Sciences, Beijing 100053; ${ }^{3}$ Department of Traditional Chinese Medicine,

College of Pharmacy, Shaanxi University of Traditional Chinese Medicine, Xianyang, Shaanxi 712046;

${ }^{4}$ Department of Agriculture and Life Sciences, Ankang University, Ankang, Shaanxi 725000; ${ }^{5}$ Department of Orthopedics, Hebei Wen'an Hospital, Langfang, Hebei 065800; ${ }^{6}$ Department of Endocrinology, Guang'anmen Hospital, China Academy of Chinese Medical Sciences, Beijing 100053, P.R. China
\end{abstract}

Received June 22, 2016; Accepted May 24, 2017

DOI: $10.3892 / \mathrm{mmr} .2017 .7467$

\begin{abstract}
The aim of the present study was to compare the different effects of berberine (Ber) and Coptischinensis extract (CCE) on a rat model of type 2 diabetes mellitus (T2DM), and the islet Rin-5f cell line was used to examine the differences between Ber and CCEand the underlying mechanisms. CCE was extracted and purified prior to analysis. Male Sprague-Dawley rats were provided with a high-fat diet to induce insulin resistance prior to injecting with streptozotocinto establish the T2DM model, the T2DM rats were treated with Ber and CCE, and blood samples and pancreatic tissues were obtained and compared to examine T2DM metabolic syndromes among the groups of rats, which included healthy rats, model rats, and model rats treated with Ber and CCE at different doses between 0 and 8 weeks. The protective effects of Ber and CCE on the Rin-5f islet cell line were also evaluated. The effects on Rin-5f cell proliferation and cell cycle, glucose-stimulated insulin release test (GSIS), the anti-apoptotic effects caused by
\end{abstract}

Correspondence to: Dr Han-Ming Cui, Department of Chinese Traditional Medicine Research and Development Center, Guang'anmen Hospital, China Academy of Chinese Medical Sciences, 5 Beixian'ge Street, Beijing 100053, P.R. China

E-mail: cui-yaoshi@163.com

Dr Xiao-Lin Tong, Department of Endocrinology, Guang'anmen Hospital, China Academy of Chinese Medical Sciences, 5 Beixian'ge Street, Beijing 100053, P.R. China

E-mail: xiaolintong66@sina.com

*Contributed equally

Key words: Coptischinensis extract, berberine, type 2 diabetes mellitus, islet $\beta$-cell, Rin-5f cell, poly ADP-ribose polymerase-1 protein fat induction, and protein expression levels of poly ADP-ribose polymerase (PARP-1) were evaluated. The results showed that the content of the prepared CCE was $96.07 \%$ for five alkaloids. When it was used for treatment of the T2DM rats, compared with Ber, metformin and rosiglitazone, the fasting blood glucose, glucosylated serum protein (GSP) and glucose infusion rate indicesin the fasting rats were ameliorated, compared with those in the T2MD rats, with no significant differences between treatment with Ber or CCE and metformin or rosiglitazone. The indices of mean optical density and fasting $\beta$-cell function index (FBCI) were different following treatment with Ber and CCE, compared with those in the model rats, which may have stimulated the pancreatic secretion of insulin. When Ber and CCE were used to examine the protective effects on Rin-5F cells, it was found that the Rin-5f cell GSIS, cell cycle, lipotoxic islet cell proliferation and protein expression of PARP-1 were altered and improved, which may have protected pancreatic islet $\beta$-cells by improving islet $\beta$-cell proliferation and the protein expression of PARP-1. CCE and Ber exerted similar effects when used for the treatment of T2MD rats, and may have stimulated the pancreatic secretion of insulin through the protective effect on islet $\beta$-cells via improving islet $\beta$-cell proliferation and the protein expression of PARP-1.

\section{Introduction}

Berberine (Ber) is an isoquinoline alkaloid isolated from Coptischinensis Franch, which differs from Coptischinensis extract (CCE) (1). Studies have shown that Ber offers potential for the treatment of type 2 diabetes mellitus (T2DM) (2-7), whereas CCE is primarily one of the components of a Chinese traditional formula for the treatment of diabetes mellitus (DM) via the prevention of associated vascular and cardiac damage, renal fibrosis and lipid metabolism (8-10). Ber is a classical natural medicine, the applications of which have attracted interest in investigations focused on the treatment of DM(11-15). The pharmacological effects of Ber on glucose metabolism 
have been shown to involve pathways, including improving insulin resistance (16), promoting insulin secretion (17-19), protecting diabetic nephropathy (20-22), modulating gut microbiota $(23,24)$, affecting phospholipid metabolites (25), preventing cardiac dysfunction in T2TM (26-28), inhibiting gluconeogenesis in the liver $(29,30)$, reducing glucose absorption and enhancing glucose consumption $(31,32)$, ameliorating hepatosteatosis and stimulating glycolysis $(33,34)$, and regulating lipid metabolism $(35,36)$. The potency of Ber in the treatment of DM is predominantly associated with its antioxidant and anti-inflammatory activities $(37,38)$, and few studies have focused on the pancreatic-derived factor of islet $\beta$-cells (39-41). The protein expression of poly ADP-ribose polymerase (PARP)-1 in islet $\beta$-cells may also be an important pathway for DM treatment (42).

Therefore, the present study selected Ber and CCE as the subjects for investigation, and their different effectson T2DM rats were examined. The indices of fasting blood glucose (FBG), glucosylated serum protein (GSP) and glucose infusion rate (GIR) in fasting rats were compared among treatment groups of rats, and the pancreatic indices of mean optical density (MOD) and fasting $\beta$-cell functional index (FBCI) were compared for the evaluation of insulin secretion. Ber and CCE were also used to investigate their protective effects on Rin-5f cells, in which results of the glucose-stimulated insulin release test (GSIS), cell cycle, lipotoxic islet cell proliferation and protein expression levels of PARP-1 were analyzed. CCE and Ber possessed equal effects in the treatment of T2MD rats, which may have stimulated the pancreatic secretion of insulin. In the Rin-5f cells, the GSIS, protection of lipotoxic islet cell proliferation and apoptosis, and the protein expression levels of PARP-1 were improved, which may protect pancreatic of islet $\beta$-cells by improving islet $\beta$-cell proliferation and the protein expression of PARP-1.

\section{Materials and methods}

Preparation and analysis of CCE. The herbal medicine Coptischinensis Franch (Guangzhou Baiyunshan Zhong Yi Pharmaceutical Co., Ltd., Guangzhou, China; batch no. 20090208) was extracted by the addition of $0.5 \%$ sulfuric acid (1:8 by weight) three times at a temperature of $100^{\circ} \mathrm{C}$ (1.5 $\mathrm{h}$ each time). The filtrates were mixed and concentrated by evaporation at $75^{\circ} \mathrm{C}$ to obtain a condensed solution (relative density of 1.07 at $55^{\circ} \mathrm{C}$ ), following which the solution was filtered and the precipitate discarded prior to adjusting the $\mathrm{pH}$ to 9.0 with calcium hydroxide (10\% by weight). The solution was then filtered and the $\mathrm{pH}$ was adjusted to 1.5 with hydrochloric acid (AR), following which sodium chloride (AR) was added to adjust the concentration (10\% by weight). The solution was agitated to mix, prior to standing for $24 \mathrm{~h}$, following which the precipitate was obtained and washed with water until a $\mathrm{pH}$ of 5.0 was obtained. The precipitate was refined three times using hydrochloric acid, sodium chloride (10\% by weight) and water, according to the above-mentioned procedure. The obtained precipitate was evaporated to dryness at $60^{\circ} \mathrm{C}$ to obtain $8 \mathrm{~kg}$ of CCE.

The sample analysis was performed on an Agilent 1200 high-performance liquid chromatography (HPLC) system (Agilent Technologies, Inc., Santa Clara, CA, USA) equipped with a diode array detector at a wavelength of $345 \mathrm{~nm}$. The HPLC column used was a Venusil XBP-C18 (Agela Technologies, Inc., Wilmington, DE, USA) analytical column (250x4.6 mm, $5 \mu \mathrm{m})$. The mobile phase composition was acetonitrile and $0.05 \mathrm{M}$ potassium dihydrogen phosphate buffer solution $(28: 72, \mathrm{v} / \mathrm{v})$ at a flow rate of $1.0 \mathrm{ml} \cdot \mathrm{min}^{-1}$. The test solution was prepared by dissolving CCE in hydrochloric acid-methanol $(1: 100, \mathrm{v} / \mathrm{v})$. The standard was prepared by dissolving the standard sepiberberine (EPI), coptisine (COP), palmatine (PAL), jatrorrhizine (JAT) and Ber in hydrochloric acid-methanol $(1: 100, \mathrm{v} / \mathrm{v})$ to obtain appropriate concentrations for CCE sample analysis. The EPI, COP, PAL, JAT and Ber standards were purchased from the National Institutes for Food and Drug Control (Beijing, China) and Shanghai Yuanye Biotechnology Co, . Ltd. (Shanghai, China).

Animals, model establishment and treatment. A total of 180 male Sprague-Dawley rats $(190 \pm 10 \mathrm{~g} ; 4$ weeks old) of SPF grade were purchased from Vital River Lab Animal Technology Co., Ltd (Beijing, China), as was the high-fat diet, which contained $18 \%$ lard, $20 \%$ sucrose, $3 \%$ egg yolk and $59 \%$ basal diet (24.0\% protein, $3.5 \%$ lipids and $60.5 \%$ carbohydrate). All experiments were approved by the Ethical Committee of Guang'anmen Hospital, China Academy of Chinese Medical Sciences (Beijing, China). The animals were cared for in accordance with the Guide for the Care and Use of Laboratory Animals of the National Institutes of Health (Bethesda, MD, USA). The rats were randomly divided into two groups; in the normal control group $(n=20)$, rats were fed with a basal diet; in the high-fat diet group $(n=160)$, rats were fed with the high-fat diet for a total of 8 weeks. The rat body weights were compared between the control group and the experimental group in eight randomly selected rats, and no significant differences in body weights were found between the two groups. The rats were randomly selected for eight hyperinsulinemiceuglycemic clamp experiments to assess insulin resistance, the results of glucose homeostasis and glucose infusion rate (GIR) are shown in Table I, with insulin resistance observed in the high-fat diet group rats. When the rats in the high-fat diet group showed significant insulin resistance, the rats were administered with an intravenous injection of streptozotocin (dissolved in $0.1 \mathrm{M}$ citrate buffer in an ice bath at a concentration of 1\%; $\mathrm{pH} 4.4$ ) at a dose of $30 \mathrm{mg} / \mathrm{kg}$ to establish the T2DM rat model. The rats in the normal diet group were administered with an intravenous injection of an equal volume of citric acid-sodium buffer solution. After 1 week, the blood glucose levels of the rats were randomly measured, and a blood glucose level of $>16.7 \mathrm{mM}$ was considered to indicate successful model establishment. The model rats were randomly divided into eight groups according to blood glucose level and body weight. The rats in the control group and model group were orally administered with distilled water every day; rats in the rosiglitazone group received rosiglitazone at a dose of $0.4 \mathrm{mg} / \mathrm{kg} / \mathrm{d}$; rats in the metformin, Ber and CCE groups were administrated with metformin, Ber and CCE at a dose of $100 \mathrm{mg} / \mathrm{kg} / \mathrm{d}$ (Table II), respectively. The rats in each group were administered with distilled water or drugs for 8 weeks.

Measurement of fasting blood glucose and glycosylated serum protein. The rats were fasted overnight for $12 \mathrm{~h}(8.00$ p.m-8.00 
a.m.) with free access to water. The FBG was measured the following morning using a blood glucose meter via the tail vein. The blood serum was separated by centrifugation at $4,000 \mathrm{x} \mathrm{g}$ for $15 \mathrm{~min}$ at $4^{\circ} \mathrm{C}$ to determine the levels of glycosylated serum protein (GSP).

Hyperinsulinemic-euglycemic clamp experiment. The rats were fastedovernightpriortothehyperinsulinemic-euglycemic clamp experiment with free access to water. The rats were anesthetized via $2 \%$ sodium pentobarbital intraperitoneal injection, the dose of which was calculated by body weight at $40 \mathrm{mg} / \mathrm{kg}$. The right carotid artery and the left jugular vein were isolated and incubated with a silica gel epidural catheter (inner diameter, $0.6 \mathrm{~mm}$; outer diameter, $1 \mathrm{~mm}$ ), which contained saline heparin $(50 \mathrm{U} / \mathrm{ml})$ to maintain patency. Arterial blood glucose was determined using a blood glucose meter. The venous catheter was connected to the tee and the vein connected to the outlet, with the inlet end connected to infusions of insulin (infusion rate $8 \mathrm{mU} / \mathrm{kg} / \mathrm{min}$, insulin albumin diluted with $0.5 \%$ bovine serum from Gibco, Thermo Fisher Scientific, Inc. (Waltham, MA, USA; lot: 1527494) and glucose (20\%) using a microcomputer digital micro-injection syringe pump from the jugular vein. The blood glucose levels of the rats were determined following of $30 \mathrm{~min}$ of insulin and glucose infusion. The blood was obtained from the jugular vein to measure glucose values. Firstly, short-acting porcine insulin (Sigma-Aldrich; Merck Millipore (Darmstadt, Germany); 1:500; batch no. 20110925) was constantly infused, and blood glucose was determined once every $10 \mathrm{~min}$. When the blood glucose level exceeded the baseline value $\pm 0.5 \mathrm{mM}, 20 \%$ glucose was infused to adjust the blood GIR on the basis of the control value $\pm 0.5 \mathrm{mM}$. The GIR was adjusted in the shortest possible time in accordance with a normal blood glucose level. The procedure was repeated until three consecutive blood glucose values were stable within the above range; the steady state value of the three average GIR values $\left(\mathrm{mg} \cdot \mathrm{kg}^{-1} \cdot \mathrm{min}^{-1}\right)$ was obtained.

Pancreatic tissue immunohistochemistry. The rats were sacrificed under anesthesia. The pancreatic tissue was isolated and embedded in paraffin prior to being cut intosections $(2 \times 2 \mathrm{~cm}$, $8 \mu \mathrm{m}$ ) for insulin immunohistochemistry (INS). The tissue sections were stained with guinea pig anti-porcine insulin antibody (cat. no. 129-10332; RayBiotech, Inc., Norcross, GA $30092 ; 1: 100)$ in the $\beta$-cells. For the second step of the DAKO antibody Envision ${ }^{\mathrm{TM}}$ system (Glostrup, Denmark), DAB was used as a color reagent for the $\beta$-cell tissue sections. The Envision procedure was as follows: Tissue sections were skimmed prior to hydration by rinsing in distilled water and were placed in TBS, to which with $0.3 \%$ hydrogen peroxide was added to block endogenous peroxidase, and then incubated for $15 \mathrm{~min}$ at $4^{\circ} \mathrm{C}$. The tissue sections were rinsed in distilled water and placed into TBS for rinsing for $5 \mathrm{~min}$, which was repeated three times. Following incubation for $2 \mathrm{~h}$ at $4^{\circ} \mathrm{C}$, TBS rinsing was performed for 5 min three times, Envision ${ }^{\mathrm{TM}}$ was added prior to incubation for $60 \mathrm{~min}$, followed by rinsing in TBS for $5 \mathrm{~min}$ three times. The DAB source chromogenic solution was used for staining for $3 \mathrm{~min}$, and color development was terminated with distilled water. The sections were then dehydrated in alcohol. A negative control experiment was
Table I. Results of the hyperinsulinemiceuglycemic clamp test prior to modeling.

\begin{tabular}{lcc}
\hline Group & $\begin{array}{c}\text { Glucose homeostasis } \\
(\mathrm{mM} / \mathrm{l})\end{array}$ & $\begin{array}{c}\text { Glucose infusion rate } \\
\left(\mathrm{mg} \cdot \mathrm{kg}^{-1} \cdot \mathrm{min}^{-1}\right)\end{array}$ \\
\hline Control & $5.0 \pm 0.1$ & $23.38 \pm 1.26$ \\
High-fat diet & $5.0 \pm 0.2$ & $20.27 \pm 1.60^{\mathrm{a}}$ \\
\hline
\end{tabular}

Data are presented as the mean \pm standard deviation $(\mathrm{n}=8) .{ }^{\mathrm{a}} \mathrm{P}<0.05$, vs. control.

also performed, in which TBS was used instead of primary antibody as a negative blank control. The results were observed under a light microscope (Nikon Corporation, Tokyo, Japan). The MOD was obtained from Sigma Photo Prosoftware version 5.5.1 (Sigma-Aldrich; Merck Millipore) by counts. The FBCI was calculated based on fasting insulin level (FINS) and FBG using the following formula: FBCI = FINS / FBG.

Cell culture. The Rin-5f cells were cultured in medium comprising fetal bovine serum (FBS) diluted in 1640 culture medium $(1: 10, v / v)$. When $\sim 80 \%$ of the Rin-5f cells had adhered to the bottom of the dish, the original culture medium was discarded and replaced with 5\% BSA in 1640, and cultured for $36 \mathrm{~h}$ for synchronized cultivation. The Rin-5f cell line was provided by the Cell Library of Wuxi Medical School, Jiangnan University (Wuxi, China). The 1640 culture medium, FBS and antibiotic-antimycotic were purchased from Invitrogen; Thermo Fisher Scientific, Inc. The kit used for western blot analysis was purchased from GE Healthcare Life Sciences (Chalfont, UK). PARP-1 antibody (cat. no. AE90773Mu) was purchased from Cell Signaling Technology, Inc. (Danvers, MA, USA); HRP-labeled goat anti-mouse IgG $(\mathrm{H}+\mathrm{L})$ (cat. no. SN133) were all obtained from NanJing KeyGen Biotech Co., Ltd. (Nanjing, China), $\beta$-actin (cat. no. P0068) were obtained from Beyotime Institute of Biotechnology (Shanghai, China). The FITC Annexin V Apoptosis Detection kit II was purchased from BD Biosciences (Franklin Lakes, NJ, USA). Fatty acid-free bovine serum albumin (FFA) and other chemical reagents were purchased from Sigma-Aldrich; Merck Millipore. FFA was dissolved with $0.1 \mathrm{M} \mathrm{NaOH}$ solution at $70^{\circ} \mathrm{C}$, and then shaken for $10 \mathrm{~min}$ prior to filtering through a $0.22-\mu \mathrm{m}$ filter as the stock solution at a concentration of $100 \mathrm{mM}$. The FFA solution was dissolved in deionized water to obtain a solution concentration of $50 \mathrm{~g} / \mathrm{l}$ at $55^{\circ} \mathrm{C}$, prior to filtering through a $0.22-\mu \mathrm{m}$ filter. A solution was then prepared, which contained 5\% FBS and $0.25 \mathrm{mM}$ FFA in 1640 culture medium.

A Synergy 2 microplate reader (BioTek Instruments, Inc., Winooski, VT, USA) was used to measure the absorption. The mRNA expression levels were detected using the line-general-time fluorescence quantitative polymerase chain reaction system (Line-Gene 9600; Hangzhou Bioer Technology Co., Ltd., Hangzhou, China). An RNA prep pure cell kit (cat. no. DP430) was obtained from Tiagen Biotech Co., Ltd. (Beijing, China). PCR was performed using a Verso 1-step QRT-PCR kit Plus ROX vial (cat. no. AB-4100/A; Thermo Fisher Scientific, Inc.), which contained $50 \mu$ l Verso 
Table II. Details of the rats in each experimental group.

\begin{tabular}{lcccc}
\hline Group & $\mathrm{n}$ & Blood glucose $(\mathrm{mM})$ & Body weight $(\mathrm{g})$ & Dose $(\mathrm{mg} / \mathrm{kg} / \mathrm{d})$ \\
\hline Control & 20 & $4.8 \pm 1.1^{\mathrm{a}}$ & $369.6 \pm 19.6$ & Distilled water \\
Model & 15 & $23.0 \pm 3.8$ & $372.2 \pm 30.4$ & Distilled water \\
Metformin & 15 & $23.1 \pm 3.7$ & $370.8 \pm 39.1$ & 100 \\
Rosiglitazone & 15 & $23.0 \pm 3.9$ & $365.1 \pm 42.9$ & 0.4 \\
Ber-low & 15 & $23.3 \pm 3.7$ & $362.1 \pm 40.6$ & 50 \\
Ber-middle & 15 & $23.1 \pm 3.9$ & $362.9 \pm 39.3$ & 100 \\
Ber-high & 15 & $23.2 \pm 4.1$ & $363.1 \pm 45.5$ & 250 \\
CCE-low & 15 & $23.1 \pm 3.8$ & $355.8 \pm 54.7$ & 50 \\
CCE-middle & 15 & $23.2 \pm 3.9$ & $359.8 \pm 51.1$ & 100 \\
CCE-high & 15 & $23.1 \pm 3.9$ & $344.9 \pm 50.9$ & 250 \\
\hline
\end{tabular}

${ }^{\mathrm{a}} \mathrm{P}<0.05$ (control group vs. CCE or Ber). Ber, berberine; CCE, Coptischinensis extract.

Enzyme mix, $50 \mu 1$ yellow RT Enhancer, a 1-step QRT-PCR mix (2X $1.25 \mathrm{ml}$ ) and $25 \mu \mathrm{l}$ brown ROX dye. The fluorophore used in the reaction was Taqman (cat. no. 4304437; Thermo Fisher Scientific, Inc.). The 1-step QRT-PCR mix contained Thermo-Start ${ }^{\mathrm{TM}}$ DNA polymerase (cat. no. AB-4100/A; Thermo Fisher Scientific, Inc.), which had 5' to 3' polymerization and exonuclease activity but lacked $3^{\prime}$ to $5^{\prime}$ exonuclease activity. The kit used for cDNA synthesis and reverse transcription were from the Verso 1-step QRT-PCR kit Plus ROX vial, where the Verso ${ }^{\mathrm{TM}}$ Enzyme mix (cat. no. AB-4100/A; Thermo Fisher Scientific, Inc.) contained the reverse transcriptase enzyme for long cDNA strand generation. and also contained RNAse inhibitor to protect RNA templates from degradation (according to the manufacturer's protocol). Cycling conditions were as follows (according to the kit protocol): $50^{\circ} \mathrm{C}$ for $15 \mathrm{~min}$ for one cycle, thermostatic activation at $95^{\circ} \mathrm{C}$ for $15 \mathrm{~min}$ for one cycle, followed by 40 cycles at $95^{\circ} \mathrm{C}$ for $15 \mathrm{sec}$ and extension at $60^{\circ} \mathrm{C}$ for $60 \mathrm{sec}$ (43). Primers were as follows: forward, $5^{\prime} \mathrm{GCC}$ CTAAAGGCTCAGAACGAC3' and reverse, 5'CACCATGCC ATCAGCTACTCG3 for PARP-1; forward, 5'CACCCACTC CTCCACCTTTG3' and reverse, 5'CCACCACCCTGTTGC TGTAG3 for GAPDH. Image capture was performed using the Flurochem 8900 system (Alpha Innotech). The $2^{-\Delta \Delta C q}$ method was used for quantification (44).

Rin-5f cell survival rate assay using MTT. The Rin-5f cells were transferred into a 96 -well plate at $\sim 1 \times 10^{5}$ cells per well, following which different concentrations of the drugs were added to each well and incubated for $0,24,48$ and $72 \mathrm{~h}$ prior to the MTT assay. Culture medium without Rin-5f cells and drug-free culture medium with Rin-5f cells were used as blank and control groups, respectively. Each group was examined in triplicate $(n=3)$. The obtained absorbance values were used to calculate the Rin-5f cell survival rate (SR\%). The absorbance (A) of each well was determined using a Synergy 2 micro-plate reader at wavelength of $570 \mathrm{~nm}, \mathrm{SR} \%$ was used to evaluate the effects of Ber and CCE on Rin-5f cells, calculated using the following formula: $\mathrm{SR} \%=\left(\mathrm{A}_{\text {Drug groups }}-\mathrm{A}_{\text {blank }}\right) /\left(\mathrm{A}_{\text {Control group }}-\mathrm{A}_{\text {blank }}\right)$.

GSIS release test. The Rin-5f cells were induced with the drugs for 3 days, following which the drug was washed off, and $1.0 \mathrm{~g} / 1$ glucose was added, prior to culture in $2 \%$ BSA 1640 culture medium in a $\mathrm{CO}_{2}$ incubator at $37^{\circ} \mathrm{C}$ for $10 \mathrm{~min}$. The supernatant was aspirated, and $3 \mathrm{~g} / \mathrm{l}$ glucose was added to cells for culture in 2\% BSA 1640 culture medium for 45 min. Again, the supernatant was discarded and the cells were washed twice with the culture medium. Subsequently, $1 \mathrm{~g} / 1$ glucose was added and the cells were cultured in 2\% BSA in 1640 medium for $45 \mathrm{~min}$, following which the supernatant was discarded. The levels of insulin were measured using chemiluminescence, and the insulin release index was calculated by comparing the high glucose intake insulin value with the low glucose insulin value $(n=6)$. The experimental groups composed of control group, glibenclamide group, Ber groups at doses of 5, 20, 100, 150 and $250 \mu \mathrm{M}$, and CCE group at doses of 5,20, 100, 150 and $250 \mu \mathrm{M}$.

Analysis of cell cycle. The Rin-5f cells were transferred into a 6 -well plate at $\sim 1 \times 10^{5}$ in each well for culture until $80 \%$ of cells had adhered to the bottom of the plate. Culture synchronization was performed for $36 \mathrm{~h}$ prior to discarding of the original culture medium. The cells were divided into a control group (5\% BSA in 1640 medium) and drug-induced groups (0.25 mM FFA, BerorCCE at a dose of $100 \mu \mathrm{M}$ in 5\% BSA in 1640 medium) with three wells for each group. Following drug intervention for $48 \mathrm{~h}$ at $37^{\circ} \mathrm{C}$, the trypsin-digested cells were collected by centrifugation $(1,350 \mathrm{xg})$ at $4^{\circ} \mathrm{C}$ for $15 \mathrm{~min}$, and the suspended and adherent cells were collected and washed twice with pre-cooled PBS at $4^{\circ} \mathrm{C}$. The cells were then resuspended with binding buffer to a cell concentration of $10^{6} / \mathrm{ml}$, and $100 \mu \mathrm{l}$ of each sample cell suspension was collected and added to10 $\mu \mathrm{l}$ propidium iodide solution (PI) and $100 \mathrm{mg} / \mathrm{l}$ RNA enzyme-binding buffer. The mixture was incubated at $37^{\circ} \mathrm{C}$ for $30 \mathrm{~min}$ in a water bath. Subsequently, $400 \mu \mathrm{l}$ of the binding buffer was added into each sample fluid, and cell cycle and distribution analyses were performed on the samples using flow cytometry.

MTT determination of the inhibition of lipotoxic islet cell proliferation. The Rin-5f cells were seeded into a 96-well plate (20,000 per well), following cell cultivation for synchronization. Different concentrations of the drug and $0.25 \mathrm{mM}$ palmitic acid, low glucose 1640 culture medium, and 2\% 


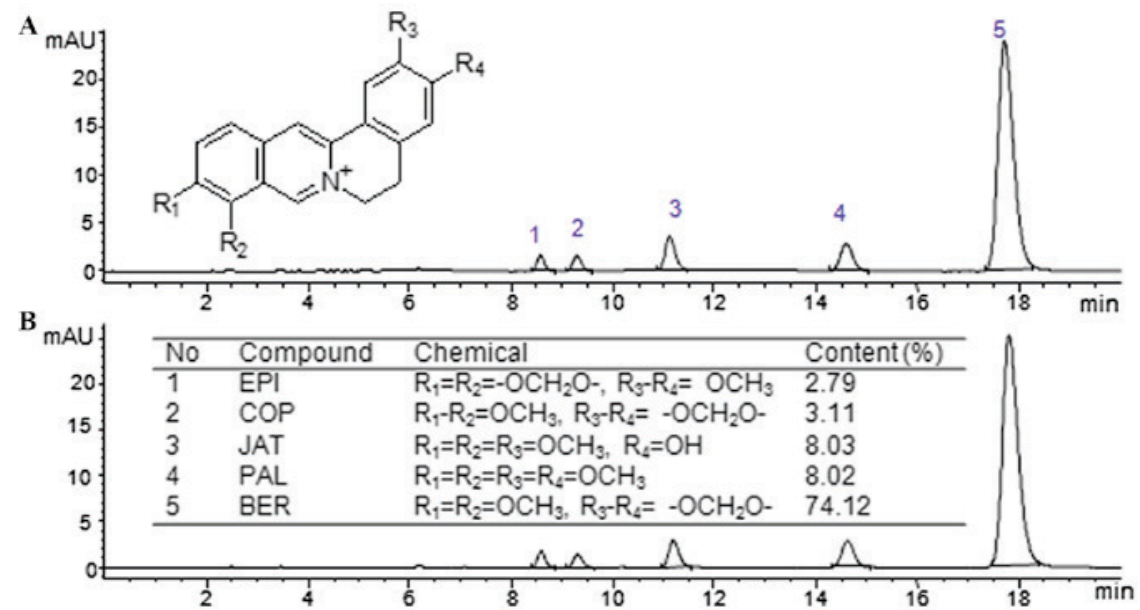

Figure 1. High performance liquid chromatography, chemical structures and contents for CCE determination. Chromatography of (A) standard solution and (B) test solution. Peaks 1-5 represent EPI, COP, JAT, PAL and Ber, respectively. EPI, epiberberine; COP, coptisine; PAL, palmatine; JAT, jatrorrhizine; Ber, berberine.

BSA, respectively, were added to the wells, with six parallel wells for each group. The MTT assay was performed using an MTT kit, according to the manufacturer's protocol, following cultivation for $24 \mathrm{~h}$. The experiments were repeated three times. The absorbance (A) values were used to calculated islet cell proliferation inhibition rate (PIR) as follows: PIR $=\left[1-\left(A_{d}-A_{b}\right) /\left(A_{c}-A_{b}\right)\right] \times 100 \%$, where $A_{d}, A_{c}$ and $A_{b}$ represented the drug induced group, control group and blank group, respectively. The were 13 groups, including the control group, Ber groups at doses of 2, 10, 50, 100, 250 and $500 \mu \mathrm{M}$ and the CCE groups.

Protective effects of Ber and CCE on high fat-induced islet cell apoptosis. Cohest apoptotic Rin-5f cell staining was performed to examine apoptosis. Sterilized slides were placed into 6-well cell culture plates; with $5 \times 10^{5}$ islets cells in each well. Following incubation for the synchronization, when cells had adhered to the bottom of the plate, 1640 low glucose culture medium, $0.25 \mathrm{mM}$ palmitate and $2 \% \mathrm{BSA}$ were added to induce cell apoptosis, following which the drugs were added for $24 \mathrm{~h}$ prior to removal of the culture medium. Following washing with PBS three times, the slides were removed and stained according to the manufacturer's protocol of the cohest staining kit. The numbers of apoptotic cells were counted in 100 cells per field on each slide in five fields of view under a fluorescence microscope. The apoptotic rate was calculated as follows: Apoptotic rate $=$ number of apoptotic cells $/ 500 \times 100 \%$. The experimental groups comprised Ber and CCE at doses of 2, 10, 50, 100, 250 and $500 \mu \mathrm{M}$ respectively.

Determination of islet cell apoptosis. The high fat-induced Rin-5f cells were divided into a control group (culture medium), model group $(0.25 \mathrm{mM}$ FFA, 5\% BSA, 1640), Ber $(100 \mu \mathrm{M})$ and $\mathrm{CCE}(100 \mu \mathrm{M})$, prior to induction for $24 \mathrm{~h}$. The cells $\left(5 \times 10^{5}\right.$ islets cells per well) were stained according to the Annexin V-FITC/PI double staining method. The culture medium was removed and the cells were washed twice with Dulbecco's phosphate-buffered saline (D-PBS), following which $0.25 \%$ trypsin was added to digest the cells, and the cell suspension was collected by centrifugation at $4^{\circ} \mathrm{C}$ for $5 \mathrm{~min}$ at $1,350 \mathrm{x} \mathrm{g}$

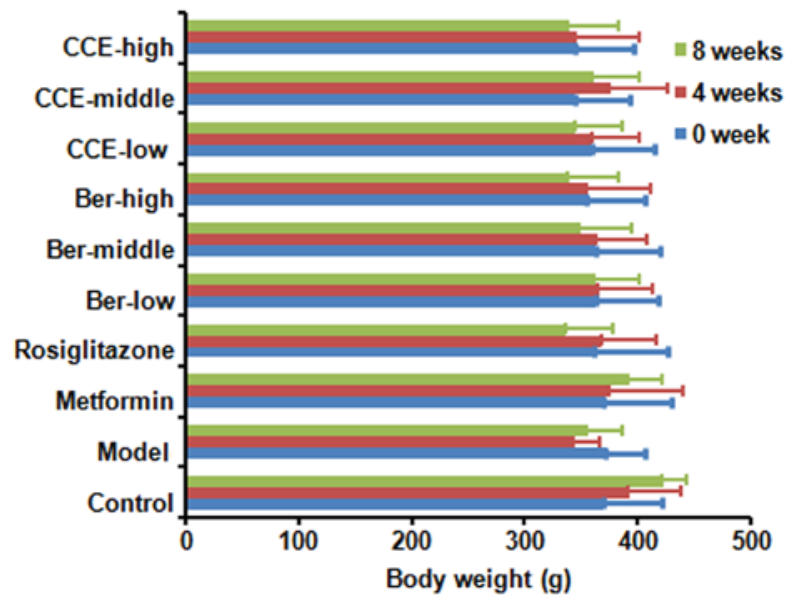

Figure 2. Graph of the changes in rats body weights in each group. Data are presented as the mean \pm standard deviation.

to remove the medium. The precipitate was resuspended with $0.5 \mathrm{ml}$ binding buffer, following which $5 \mu \mathrm{l}$ Annexin V-FITC reagent and $5 \mu \mathrm{l}$ PI were added prior to vortexing for $1 \mathrm{~min}$. The mixture was incubated at room temperature for $20 \mathrm{~min}$ in the dark. The binding of Annexin V-FITC was measured using flow cytometry to obtain the V-positive cell number and the mean fluorescence intensity (excitation wavelength, $488 \mathrm{~nm}$; emission wavelength, $530 \mathrm{~nm}$ ). A total of $1.0 \mathrm{ml}$ of sample was analyzed for positive expression rate detection and adjusted to $1 \times 10^{4}$ cells in each vial. The results were presented on a bivariate flow cytometry scatter plot. The lower left quadrant, the upper right quadrant and the lower right quadrant represent live cells $\left(\mathrm{FITC}^{-} / \mathrm{PI}^{-}\right)$, necrotic cells $\left(\mathrm{FITC}^{+} / \mathrm{PI}^{+}\right)$and apoptotic cells $\left(\mathrm{FITC}^{+} / \mathrm{PI}^{-}\right)$, respectively.

Western blot analysis of the protein expression of PARP-1 in apoptotic islet cells. The Rin-5f cells were seeded into a $100 \mathrm{~mm}$ petri-dishes at a concentration of $10^{6}$ cells per well. When $80 \%$ of the cells had adhered to the bottom of the wells, culture synchronization was performed for $36 \mathrm{~h}$, prior to discarding of the culture medium. The cells were divided 
Table III. Hyperinsulinemic-euglycemic clamp test results of experimental groups.

\begin{tabular}{lccc}
\hline Group & $\mathrm{n}$ & Glucose $(\mathrm{mM})$ & $\mathrm{GIR}\left(\mathrm{mg} \cdot \mathrm{kg}^{-1} \cdot \mathrm{min}^{-1}\right)$ \\
\hline Control & 6 & $5.0 \pm 0.1$ & $24.01 \pm 2.26 \mathrm{a}$ \\
Model & 6 & $4.9 \pm 0.2$ & $9.45 \pm 1.47$ \\
Metformin & 6 & $5.0 \pm 0.2$ & $15.64 \pm 1.82^{\mathrm{a}}$ \\
Ber-high & 6 & $5.1 \pm 0.3$ & $16.65 \pm 2.48^{\mathrm{a}}$ \\
CCE-high & 6 & $5.0 \pm 0.2$ & $15.65 \pm 1.33^{\mathrm{a}}$ \\
\hline
\end{tabular}

${ }^{\mathrm{a}} \mathrm{P}<0.01$, vs. model. GIR, glucose infusion rate; Ber, berberine; CCE, Coptischinensis extract.

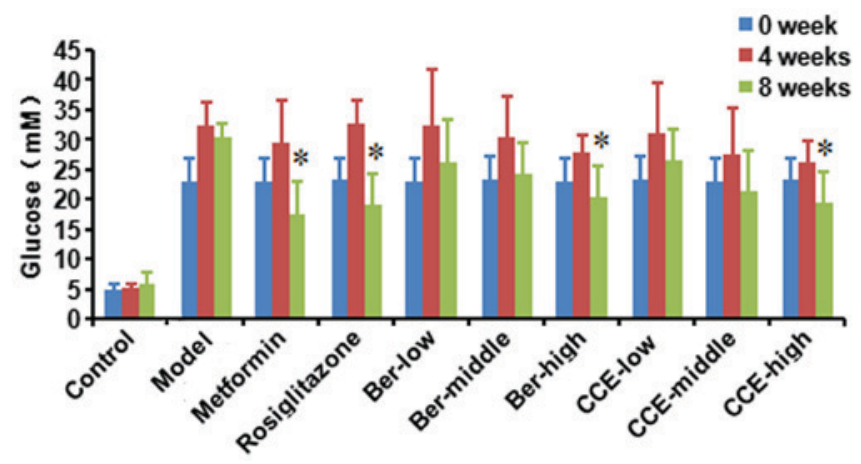

Figure 3. Graph showing the changes in rat FBG in each group. Data are presented as the mean \pm standard deviation. FBG, fasting blood glucose ${ }^{*} \mathrm{P}<0.05$, compared with the model group rats.

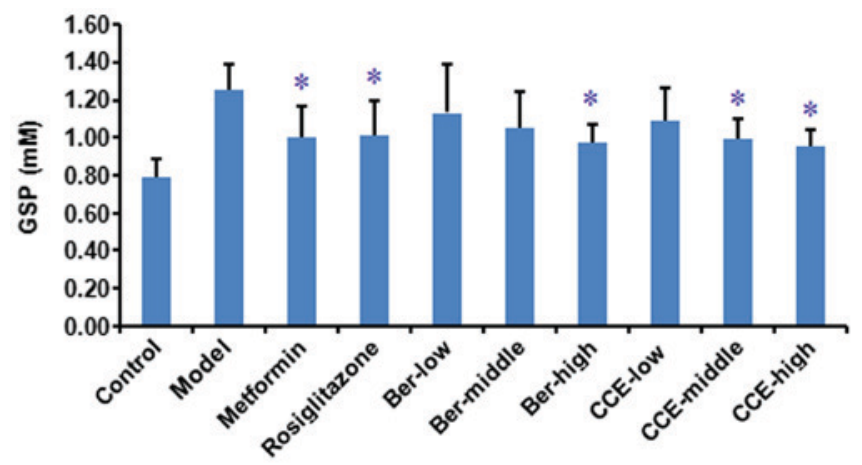

Figure 4. Graph showing the levels of GSP of rats in each group. Data are presented as the mean \pm standard deviation. GSP, glucosylated serum protein. ${ }^{*} \mathrm{P}<0.05$, compared with the model group rats.

into a control group (5\% BSA, 1640 medium), model group (0.25 mM FFA, 5\% BSA, 1640 medium) and drug groups (Ber or CCE, $0.25 \mathrm{mM}$ FFA, $5 \%$ BSA, 1640 medium), prepared at doses of 50,100, 150 and $200 \mu \mathrm{M}$ for Ber and for CCE. The cells were incubated for $24 \mathrm{~h}$ prior to digestion with protein lysate to extract proteins at $4^{\circ} \mathrm{C}$. The protein concentrations were determined according to the Bradford method as follows: For each $50 \mu \mathrm{g}$ protein sample, isolation was performed by adding $130 \mathrm{ml}$ polyacrylamide and $1 \mathrm{ml}$ SDS gel per liter, followed by transfer onto a cellulose acetate membrane, and then blocked at room temperature with tris-buffered saline

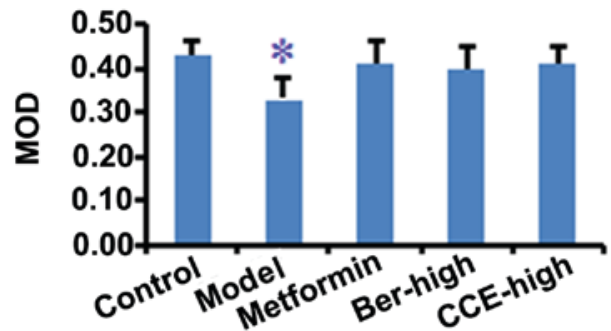

Figure 5. Pancreatic tissue immunochemistry and MOD results of each group of rats. Data are presented as the mean \pm standard deviation. ${ }^{*} \mathrm{P}<0.05$ in the model group rats compared with the other groups. MOD, mean optical density.

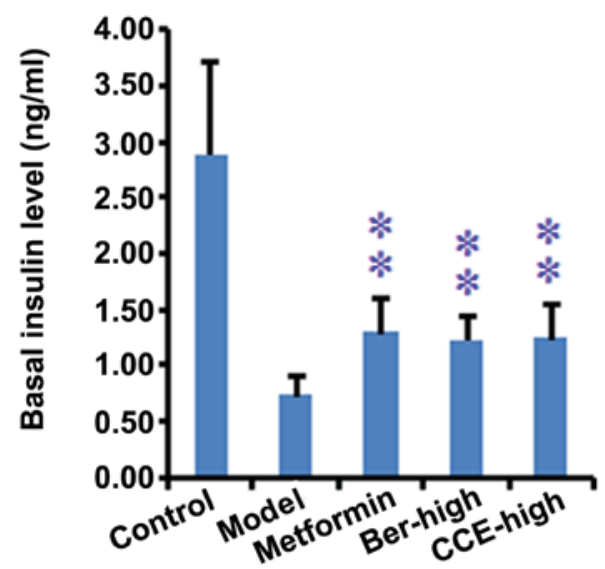

Figure 6. Basal insulin levels in the rats in each group. ${ }^{* *} \mathrm{P}<0.01$, compared with the model group rats.

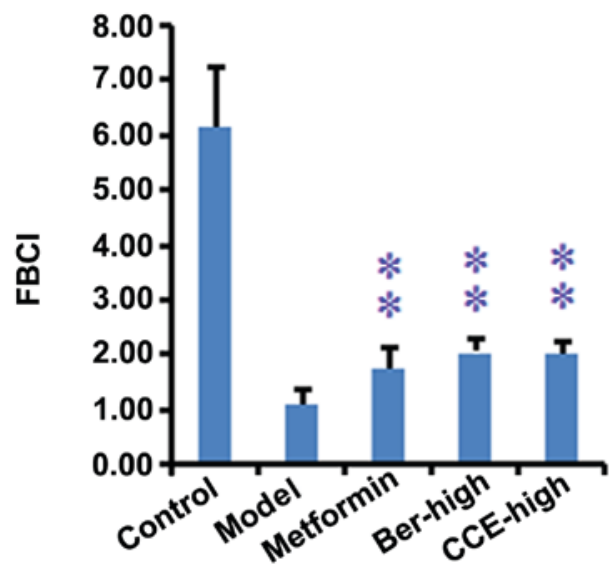

Figure 7. FBCI values of the rats in each group. ${ }^{*} \mathrm{P}<0.05$, compared with the model group rats; ${ }^{* *} \mathrm{P}<0.01$, compared with the model group rats. $\mathrm{FBCI}$, fasting $\beta$-cell function index.

with tween-20 (TBST) containing $50 \mathrm{~g} / 1$ of skim milk for $1 \mathrm{~h}$. Subsequently, specific antibody was added and incubated at $4^{\circ} \mathrm{C}$ overnight, following which the membrane was washed with TBST three times (10 min each). The membrane was then incubated with horseradish peroxidase-labeled goat anti-rabbit IgG $(1: 1,000$, diluted in $0.01 \mathrm{M}$ sodium phosphate and $0.25 \mathrm{M} \mathrm{NaCl}$ at $\mathrm{pH}$ 7.6) at room temperature for $1 \mathrm{~h}$, and then washed with TBST three times (10 min each). A sensitizing 
Table V. Glucose-stimulated insulin release test of Rin- $5 \mathrm{f}$ cells treated with Ber and CCE at doses of 5-250 $\mu \mathrm{M}$.

\begin{tabular}{lccc}
\hline & & \multicolumn{2}{c}{ Insulin release index } \\
\cline { 3 - 4 } Group & Dose $(\mu \mathrm{M})$ & Ber & CCE \\
\hline Control & - & $0.98 \pm 0.03$ & $0.98 \pm 0.03$ \\
Glibenclamide & 10 & $1.45 \pm 0.05$ & $1.45 \pm 0.05$ \\
Ber/CCE & 5 & $1.11 \pm 0.05$ & $1.15 \pm 0.05$ \\
& 20 & $1.21 \pm 0.04$ & $1.25 \pm 0.04$ \\
& 100 & $1.32 \pm 0.06^{\mathrm{a}}$ & $1.37 \pm 0.06^{\mathrm{a}}$ \\
& 150 & $1.15 \pm 0.05$ & $1.19 \pm 0.05$ \\
& 250 & $1.06 \pm 0.03$ & $1.08 \pm 0.03$ \\
\hline
\end{tabular}

Data are presented as the mean \pm standard deviation. ${ }^{\mathrm{a}} \mathrm{P}<0.05$, compared with the control. Ber, berberine; CCE, Coptischinensis extract.

Table VI. Proliferation inhibition rate of Ber and CCE on lipotoxic islet cell proliferation.

\begin{tabular}{lccc}
\hline Dose $(\mu \mathrm{M})$ & $\begin{array}{c}\text { Ber } \\
\text { survival } \\
\text { rate }(\%)\end{array}$ & $\begin{array}{c}\text { CCE } \\
\text { survival } \\
\text { rate }(\%)\end{array}$ & $\begin{array}{c}\text { Control } \\
\text { survival } \\
\text { rate }(\%)\end{array}$ \\
\hline 2 & $55.6 \pm 4.8$ & $53.5 \pm 5.4$ & \\
10 & $46.8 \pm 5.4$ & $42.9 \pm 3.8$ & \\
50 & $45.6 \pm 3.9$ & $40.4 \pm 4.2$ & $54.3 \pm 4.25$ \\
100 & $40.2 \pm 4.5^{\text {a }}$ & $36.9 \pm 4.25^{\text {a }}$ & \\
250 & $49.8 \pm 5.2$ & $45.4 \pm 4.0$ & \\
500 & $54.6 \pm 4.9$ & $49.9 \pm 4.3$ & \\
\hline
\end{tabular}

${ }^{\mathrm{a}} \mathrm{P}<0.05$. (control group vs. Ber or CCE at a dose of $100 \mu \mathrm{M}$ ). Data are presented as the mean \pm standard deviation. Ber, berberine; CCE, Coptischinensis extract.

reagent kit was used to detect chemiluminescent substrate. The Flurochem 8900 image acquisition system and Alpha View software version 3.0 (Protein Simple Bioscience and Technology Co., Ltd., Shanghai, China) were used for image capture and scanning for densitometric analysis, respectively.

Statistical analysis. Statistical analysis was performed on SPSS 11.5 software (SPSS, Inc., Chicago, IL, USA). An independent-samples t-test was used for intergroup comparison. All data are presented as the mean \pm standard deviation. $\mathrm{P}<0.05$ was considered to indicate a statistically significant difference.

\section{Results}

CCE sample analysis. The CCE was analyzed according to the developed HPLC method, the contents of EPI, COP, JAT, PAL and Ber were 2.79, 3.11, 8.03, 8.02 and $74.12 \%$ respectively. The content of the five alkaloids was $96.07 \%$. The contents, 
chemical structures and HPLC chromatography results for CCE alkaloid determination are shown in Fig. 1.

Body weights of the rats. The body weights in the control group of normal rats gradually increased between 0 and 8 weeks, which was also observed in the metformin group rats. In the model group, the body weights initially decreased and then increased slowly, whereas the body weights gradually decreased in the CCE-high group and Ber-high group. In the rosiglitazone group, body weights initially increased and then decreased as in the CCE and Ber groups (Fig. 2). Where rat health was affected by severe T2DM, body weights decreased initially (0-4 weeks) between a stage of severe disease and recovery, and then increased gradually (5-8 weeks). In each drug group, no decreases in body weights were observed between 0 and 4 weeks in each, including the rosiglitazone group, due to the protective effects of the drug. The body weights of rats were increased in the met form in group. Metformin is a biguanideantihyperglycemic agent used for the treatment of non-insulin-dependent DM, which may explain the increase in body weight.

$F B G$ and GSP. The FBG levels were measured in each group; the FBG in the control group of normal rats was normal during the 8 weeks at a range of 3.9-7.2 $\mathrm{mM}$. The FBG levels in rats of the metformin and rosiglitazone groups were 17.4 and $19.1 \mathrm{mM}$ at 8 weeks, which were significantly different, compared with the levels in the model group rats $(\mathrm{P}<0.05)$. The FBG levels in the rats of the CCE-high group and Ber-high group were 19.5 and $20.4 \mathrm{mM}$ at 8 weeks, which were also significantly different, compared with levels in the model group rats $(\mathrm{P}<0.05)$. No differences in FBG were found in the CCE-high group and Ber-high group, compared with the metformin or rosiglitazone groups. The trend of FBG followed an initial increase (4 weeks) and subsequent decrease ( 8 weeks), with the exception of the control group. The decreases in FBG were associated with the increased doses of the CCE and Ber (Fig. 3), and the decreases in GSP were associated with the increased doses of CCE and Ber (Fig. 4).

Hyperinsulinemic-euglycemic clamp test. It was found that the GIR of the model group rats was significantly decreased, compared with the normal control group, metformin group, Ber-high group and CCE-high group rats in the hyperinsulinemic-euglycemic clamp experiment $(\mathrm{P}<0.01)$. Following drug intervention with metformin, Ber or CCE, GIR was significantly increased $(\mathrm{P}<0.01$; Table III).

Pancreatic tissue immunohistochemistry, insulin levels and $F B C I$. The INS results showed that, in the control group of normal rats, pancreatic tissue was stained dark brown yellow in color. The islet cells were expressed at a high level and were diffuse in the central region of the pancreatic tissue. In the model group rats, diffuse islet cells were observed in lower number, compared with the normal group, and were brown in color. The islet cells in the metformin, CCE-high group and Ber-high group rats were distributed in the central region of the pancreatic tissue and brown in color, the expression of which was high, compared with that in the model group rats. The MOD values obtained from each group were compared, and

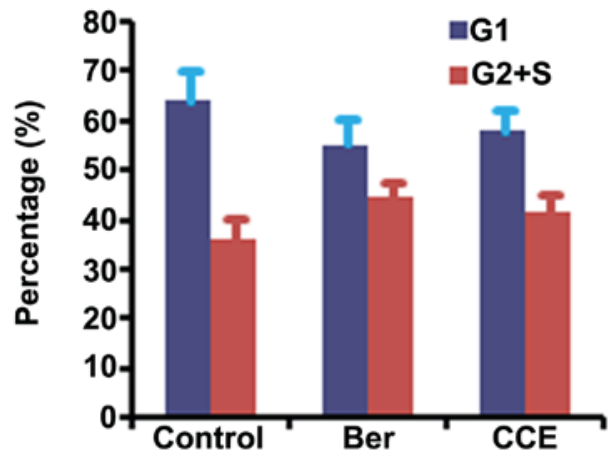

Figure 8 . Rin-5f cell cycle induction byBer and CCE. Ber, berberine; CCE, Coptischinensis extract.

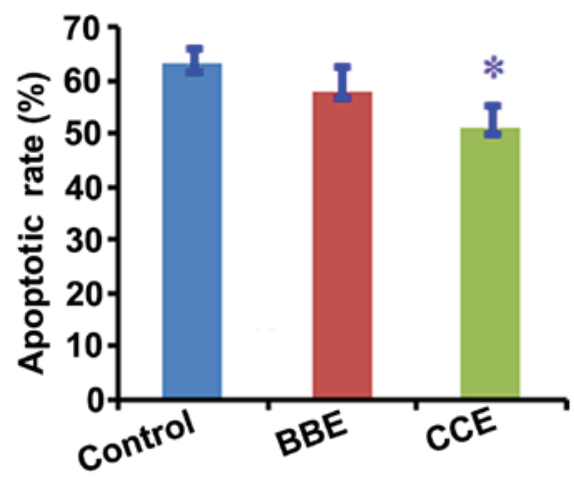

Figure 9. Proportions of apoptoticRin-5f cells in the Berand CCE groups. ${ }^{*} \mathrm{P}<0.05$ in the CCE group, compared with the control group. Ber, berberine; CCE, Coptischinensis extract.

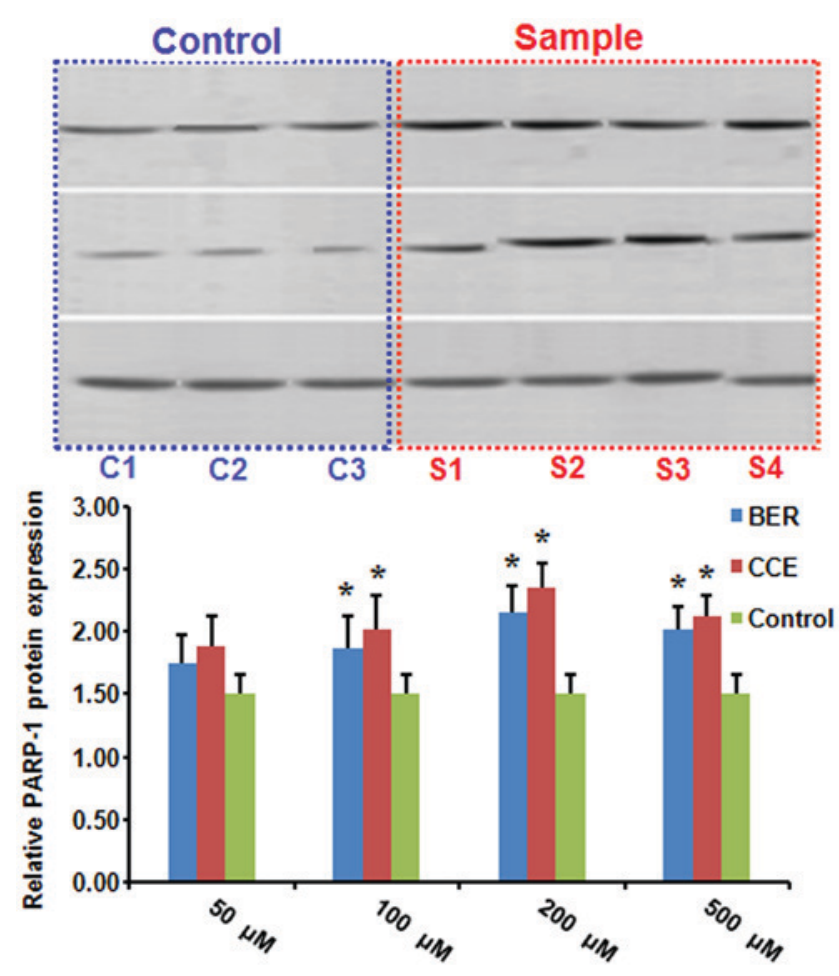

Figure 10. Grayscale plots oftheexpression of PARP-1 and relative protein expression in Rin-5f cells at $24 \mathrm{~h}$. C1-C3 represent the control groups, S1-S4 represent doses of $50,100,200$ and $500 \mu \mathrm{M}$, respectively. ${ }^{*} \mathrm{P}<0.05$ in the CCE and Ber groups, compared with the control group. PAPR-1, poly ADP-ribose polymerase; Ber, berberine; CCE, Coptischinensis extract. 
the lowest MOD was recorded in the model group, which was significantly lower, compared with that of the normal control group $(\mathrm{P}<0.05)$. Following intervention with metformin, $\mathrm{CCE}$ or Ber, the MOD values were significantly higher, compared with that in the model group $(\mathrm{P}<0.05)$, however, no significant differences were found among the drug treatment groups (Fig. 5).

The basal insulin levels obtained from each group were also compared, the lowest of which was present in the model group rats $(0.74 \pm 0.18)$, which was significantly $(\mathrm{P}<0.01)$ lower, compared with that in the control group rats $(2.89 \pm 0.82)$, and was significantly higher, compared with those of the metformin, CCE or Ber drug intervention groups $(\mathrm{P}<0.01)$. No significant differences were found among three drug treatment groups (Fig. 6).

The FBCI values obtained from each group were also compared, the lowest of which was present in the model group rats $(1.08 \pm 0.27)$, which was significantly $(\mathrm{P}<0.01)$ lower than that in the control group rats $(6.14 \pm 1.09)$, and was significantly higher, compared with those in metformin, CCE or Berdrug intervention groups $(\mathrm{P}<0.05)$. No significant differences were found among the three drug treatment groups (Fig. 7).

Rin-5f cell survival rate assay using MTT. According to the SR\% formula, the SR\% of Ber and CCE were determined at doses of $2,10,50,100,250$ and $500 \mu \mathrm{M}$, respectively. The results are shown in Table IV. There was no effect on the survival rate of Rin-5f cells treated with Ber and CCE up to $500 \mu \mathrm{M}$.

GSIS test on Rin-5f cells. The GSIS of Ber and CCE were determined at doses of 5, 20, 100, 150 and $250 \mu \mathrm{M}$ (Table V). The results showed that Ber and CCE increased GSIS of the Rin-5f cells at a dose of $100 \mu \mathrm{M}(\mathrm{P}<0.05)$, compared with the control group. Ber and CCE promoted the secretion of insulin, however, this was to a lesser degree, compared with that of glibenclamide.

Analysis of Rin-5f cell cycle. Following analysis of the cell cycle induced by $0.25 \mathrm{mM}$ FFA prior to Ber and CCE, the G1 stage of the Rin-5f cell cycle was decreased, whereas the G2 and $\mathrm{S}$ cell cycle stages were increased (Fig. 8). No significant differences were found between the control group and Ber or CCE group.

Effects of Ber and CCE on lipotoxic islet cell proliferation. An MTT assay was used to examine the effects of Ber and CCE on lipotoxic islet cell proliferation. The PIR was determined in each group (Table VI), which was decreased significantly by Ber and CCE at doses of $100 \mu \mathrm{M}$, compared with that in the control group $(\mathrm{P}<0.05)$. The effect of Beronlipotoxic islet cell proliferation was with dose-dependent at the dose range of $2-500 \mu \mathrm{M}$.

Determination apoptosis of Rin-5f cells. Following induction of the Rin-5f cells with $0.10,0.25$ and $0.5 \mathrm{mM} \mathrm{FFA}$ for $24 \mathrm{~h}$, the apoptosis of Rin-5f cells was examined at each period of time under a microscope. The cohest staining in the $0.5 \mathrm{mM}$ FFA-induced group showed cell shrinkage into a round or oval shape, synapses had disappeared, cells were floating or suspended in medium with loss of adherent growth, and a large number of vacuoles were apparent with no visible nuclei. In the $0.25 \mathrm{mM}$ FFA-induced group, there was partial cell shrinkage and adherent growth, and nuclei were visible. The numbers of apoptotic cells in each group were increased with increasing dose and time. The apoptosis of Rin-5f cells was determined using a Annexin V/FITC/PI double-labeled kit and flow cytometry to obtain the proportion of apoptotic Rin-5f cells in each group (Fig. 9). No significant difference in the proportions of apoptotic $\beta$ Rin- $5 \mathrm{f}$ cells were observed in the groups at $6 \mathrm{~h}$, however, apoptosis was significantly decreased following treatment with Ber or CCE at a dose of $100 \mu \mathrm{M}$ for $24 \mathrm{~h}$. There was a significant difference between the CCE group and control group $(\mathrm{P}<0.05)$.

Effects on islet cell protein expression of PARP-1. For each group, the grayscale of the protein expression ofPARP-1was plotted for the Rin-5f cells at $24 \mathrm{~h}$ (Fig. 10), which revealed higher gray values in the sample groups, compared with the control group. The relative protein expression was determined and compared between the sample group and control group. The protein expression levels were significantly increased in the Ber and CCE groups at doses of 100,200 and 500 $\mu \mathrm{M}$. The dose of $200 \mu \mathrm{M}$ had a more marked effect, compared with the other doses.

\section{Discussion}

The present study developed a simple preparation method to obtain CCE with a purity of $96.07 \%$ for alkaloids from Coptischinensis Franch. The systematic pharmacological function of the anti-DM treatments of Ber and CCE were investigated using a T2MD rat model and the Rin-5f cell line. When CCE was used to treat T2DM rats and compared with Berat 8 weeks, the FBG of the rats was reduced. No significant differences were found between Ber or CCE and metformin or rosiglitazone; the FBG and GSP values were decreased significantly in all of the drug groups with dose-dependence. Ber and CCE increased GIR via improving insulin secretion.

When Ber and CCE were used to examine their effects on Rin-5f cells no toxicity towards the Rin-5f cells was observed; IRI and GSIS were increased, cell cycle was altered showing a decrease in G1 and an increase in G2+S. Ber and CCE exhibited a protective effect on lipotoxic islet cell proliferation, which was associated with the increased protein expression of PARP-1. CCE was more effective than Ber on altering the protein expression of PARP-1.

In conclusion, $\mathrm{CCE}$ and Ber possessed similar efficacies in the treatment of T2MD rats, the effects of which may have occurred through stimulating the pancreatic secretion of insulin, which may be associated with their protective role on islet $\beta$-cells by increasing islet $\beta$-cell proliferation and the protein expression of PARP-1.

\section{Acknowledgements}

The present study was supported by the Technology Major Projects for Major New Drugs Innovation and Development (grant no. 2011ZX09102-011-08), the National Basic Research Program (973 Program; grant no. 2010CB530601), the National 
Nature Science Foundation of China (grant no. 81541083) and the Science Foundation of China Academy of Chinese Medical Science (grant no. ZZ0708074).

\section{References}

1. Mao T, Yan Q, Zhou F and Shen YZ: Isolation and identification of berberine from cell cultures of Coptis chinensis. Chin J Biotechnol 13: 193-199, 1997.

2. Ríos JL, Francini F and Schinella GR: Natural products for the treatment of Type 2 diabetes mellitus. Planta Med 81: 975-994, 2015.

3. Sun SF, Zhao TT, Zhang HJ, Huang XR, Zhang WK, Zhang L, Yan MH, Dong X, Wang H, Wen YM, et al: Renoprotective effect of berberine on type 2 diabetic nephropathy in rats. Clin Exp Pharmacol Physiol 42: 662-670, 2015.

4. Di Pierro F, Bellone I, Rapacioli G and Putignano P: Clinical role of a fixed combination of standardized Berberis aristata and Silybum marianum extracts in diabetic and hypercholesterolemic patients intolerant to statins. Diabetes Metab Syndr Obes 8 : 89-96, 2015

5. Chang W, Chen L and Hatch GM: Berberine as a therapy for type 2 diabetes and its complications: From mechanism of action to clinical studies. Biochem Cell Biol 93: 479-486, 2015.

6. Lan J, Zhao Y, Dong F, Yan Z, Zheng W, Fan J and Sun G: Meta-analysis of the effect and safety of berberine in the treatment of type 2 diabetes mellitus, hyperlipemia and hypertension. J Ethnopharmacol 161: 69-81, 2015.

7. Dong Y, Chen YT, Yang YX, Zhou XJ, Dai SJ, Tong JF, Shou D and Li C: Metabolomics study of type 2 diabetes mellitus and the antidiabetic effect of berberine in zucker diabetic fatty rats using Uplc-ESI-Hdms. Phytother Res 30: 823-828, 2016.

8. Yi Q, He XE, Luo KF, Zhang GS, Liu YH, Xue Q, Hou N, Chen WL and Luo JD: Protection of long-term treatment with huang-lian-jie-du-tang on vascular endothelium in rats with type 2 diabetes mellitus. Curr Ther Res Clin Exp 73: 174-185, 2012.

9. Li CB, Li XX, Chen YG, Gao HQ, Bu PL, Zhang Y and Ji XP: Huang-lian-jie-du-tang protects rats from cardiac damages induced by metabolic disorder by improving inflammation-mediated insulin resistance. PLoS One 8: e67530, 2013.

10. Wu JS, Shi R, Lu X, Ma YM and Cheng NN: Combination of active components of Xiexin decoction ameliorates renal fibrosis through the inhibition of NF- $\mathrm{kB}$ and TGF- $31 / \mathrm{Smad}$ pathways in $\mathrm{db} / \mathrm{db}$ diabetic mice. PLoS One 10: e0122661, 2015.

11. Yang Z, Wang L, Zhang F and Li Z: Evaluating the antidiabetic effects of Chinese herbal medicine: Xiao-Ke-An in 3T3-L1 cells and KKAy mice using both conventional and holistic omics approaches. BMC Complement Altern Med 15: 272, 2015.

12. Chang YX, Ge AH, Donnapee S, Li J, Bai Y, Liu J, He J, Yang X, Song LJ, Zhang BL and Gao XM: The multi-targets integrated fingerprinting for screening anti-diabetic compounds from a Chinese medicine Jinqi Jiangtang Tablet. J Ethnopharmacol 164 210-222, 2015

13. Zarei A, Changizi-Ashtiyani S, Taheri S and Ramezani M: A quick overview on some aspects of endocrinological and therapeutic effects of Berberis vulgaris L. Avicenna J Phytomed 5: 485-497, 2015

14. Pang B, Zhao LH, Zhou Q, Zhao TY, Wang H, Gu CJ and Tong XL: Application of berberine on treating type 2 diabetes mellitus. Int J Endocrinol 2015: 905749, 2015.

15. Pang B, Yu XT, Zhou Q, Zhao TY, Wang H, Gu CJ and Tong XL: Effect of rhizoma coptidis (Huang Lian) on treating diabetes mellitus. Evid Based Complement Alternat Med 2015: 921416 , 2015.

16. Li F,Zhao YB, Wang DK, Zou X, Fang K and Wang KF: Berberine relieves insulin resistance via the cholinergic anti-inflammatory pathway in HepG2 cells: J Huazhong Univ Sci Technolog Med Sci 36: 64-69, 2016

17. Geng FH, Li GH,Zhang X, Zhang P, Dong MQ,Zhao ZJ,Zhang Y, Dong $\mathrm{L}$ and Gao F: Berberine improves mesenteric artery insulin sensitivity through up-regulating insulin receptor-mediated signaling in diabetic rats. Br J Pharmacol 173: 1569-1579, 2016.

18. Lu L, Zhijian H, Lei L, Wenchuan C and Zhimin Z: Berberine in combination with insulin has additive effects on titanium implants osseointegration in diabetes mellitus rats. Evid Based Complement Alternat Med 2015: 824259, 2015.
19. Yu Y, Hao G, Zhang Q, Hua W, Wang M, Zhou W, Zong S, Huang $M$ and Wen X: Berberine induces GLP-1 secretion through activation of bitter taste receptor pathways. Biochem Pharmacol 97: 173-177, 2015.

20. Zhou J, Du X, Long M, Zhang Z, Zhou S, Zhou J and Qian G: Neuroprotective effect of berberine is mediated by MAPK signaling pathway in experimental diabetic neuropathy in rats. Eur J Pharmacol 774: 87-94, 2016.

21. Tang LQ, Ni WJ, Cai M, Ding HH, Liu S and Zhang ST: The renoprotective effects of berberine and its potential impact on the expression of $\beta$-arrestins and ICAM-1/VCAM-1 in streptozocin induced-diabetic nephropathy rats. J Diabetes, November 3, 2015 (Epub ahead of print).

22. Friedemann T, Schumacher U, Tao Y, Leung AK and Schröder S Neuroprotective activity of coptisine from coptis Chinensis (Franch). Evid Based Complement Alternat Med 2015: 827308, 2015.

23. Zhang X, Zhao Y, Xu J, Xue Z, Zhang M, Pang X, Zhang X and Zhao L: Modulation of gut microbiota by berberine and metformin during the treatment of high-fat diet-induced obesity in rats. Sci Rep 5: 14405, 2015.

24. Xie W, Gu D, Li J, Cui K and Zhang Y: Effects and action mechanisms of berberine and Rhizoma coptidis on gut microbes and obesity in high-fat diet-fed C57BL/6J mice. PLoS One 6: e24520, 2011

25. Wu X, Li Y, Wang Q, Li W and Feng Y: Effects of berberine and pomegranate seed oil on plasma phospholipid metabolites associated with risks of type 2 diabetes mellitus by U-HPLC/ Q-TOF-MS. J Chromatogr B Analyt Technol Biomed Life Sci 1007: 110-120, 2015

26. Chang W, Li K, Guan F, Yao F, Yu Y, Zhang M, Hatch GM and Chen L: Berberine pretreatment confers cardioprotection against ischemia-reperfusion injury in a rat model of type 2 diabetes. J Cardiovasc Pharmacol Ther 21: 486-494, 2016.

27. Dai P, Wang J, Lin L, Zhang Y and Wang Z: Renoprotective effects of berberine as adjuvant therapy for hypertensive patients with type 2 diabetes mellitus: Evaluation via biochemical markers and color Doppler ultrasonography. Exp Ther Med 10: 869-876, 2015

28. Chang W, Zhang M, Meng Z, Yu Y, Yao F, Hatch GM and Chen L: Berberine treatment prevents cardiac dysfunction and remodeling through activation of 5 '-adenosine monophosphate-activated protein kinase in type 2 diabetic rats and in palmitate-induced hypertrophic H9c2 cells. Eur J Pharmacol 769:55-63, 2015.

29. Jiang SJ, Dong H, Li JB, Xu LJ, Zou X, Wang KF, Lu FE and Yi P: Berberine inhibits hepatic gluconeogenesis via the LKB1-AMPK-TORC2 signaling pathway in streptozotocin-induced diabetic rats. World J Gastroenterol 21: 7777-7785, 2015

30. Jhong CH, Riyaphan J, Lin SH, Chia YC and Weng CF: Screening alpha-glucosidase and alpha-amylase inhibitors from natural compounds by molecular docking in silico. Biofactors 41 : 242-251, 2015.

31. Chang W, Chen L and Hatch GM: Berberine treatment attenuates the palmitate-mediated inhibition of glucose uptake and consumption through increased 1,2,3-triacyl-sn-glycerol synthesis and accumulation in H9c2 cardiomyocytes. Biochim Biophys Acta 1864: 352-362, 2016.

32. Pirillo A and Catapano AL: Berberine, a plant alkaloid with lipid- and glucose-lowering properties: From in vitro evidence to clinical studies. Atherosclerosis 243: 449-461, 2015.

33. Xue M, Zhang L, Yang MX, Zhang W, Li XM, Ou ZM, Li ZP, Liu SH, Li XJ and Yang SY: Berberine-loaded solid lipid nanoparticles are concentrated in the liver and ameliorate hepatosteatosis in $\mathrm{db} / \mathrm{db}$ mice. Int J Nanomedicine 10: 5049-5057, 2015.

34. Zhang Y, Chang X, Song X, Chen C, Chen H, Lu Z, Gao X and Lu D: Berberine reverses abnormal expression of L-type pyruvate kinase by DNA demethylation and histone acetylation in the livers of the non-alcoholic fatty disease rat. Int J Clin Exp Med 8: 7535-7543, 2015.

35. Zhang J, Tang H, Deng R, Wang N, Zhang Y, Wang Y, Liu Y, Li F, Wang $X$ and Zhou L: Berberine suppresses adipocyte differentiation via decreasing Creb transcriptional activity. PLoS One 10: e0125667, 2015

36. Wang Z, Wu J, Zhou Q, Wang Y and Chen T: Berberine nanosuspension enhances hypoglycemic efficacy on streptozotocin induced diabetic C57BL/6 mice. Evid Based Complement Alternat Med 2015: 239749, 2015 
37. Liu C, Wang Z, Song Y, Wu D, Zheng X, Li P, Jin J, Xu N and $\mathrm{Li}$ L: Effects of berberine on amelioration of hyperglycemia and oxidative stress in high glucose and high fat diet-induced diabetic hamsters in vivo. Biomed Res Int 2015: 313808, 2015.

38. Cui E, Zhi X, Chen Y, Gao Y, Fan Y, Zhang W, Ma W, Hou W, Guo $\mathrm{C}$ and Song $\mathrm{X}$ : Coptis chinensis and myrobalan (Terminalia chebula) can synergistically inhibit inflammatory response in vitro and in vivo. Evid Based Complement Alternat Med 2014 510157, 2014.

39. Wang O, Cai K, Pang S, Wang T, Qi D, Zhu Q, Ni Z and Le Y: Mechanisms of glucose-induced expression of pancreatic-derived factor in pancreatic beta-cells. Endocrinology 149: 672-680, 2008.

40. Gastaldelli A, Ferrannini E, Miyazaki Y, Matsuda M, Mari A and DeFronzo RA: Thiazolidinediones improve beta-cell function in type 2 diabetic patients. Am J Physiol Endocrinol Metab 292: E871-E883, 2007.
41. Guardado-Mendoza R, Davalli AM, Chavez AO, Hubbard GB, Dick EJ, Majluf-Cruz A, Tene-Perez CE, Goldschmidt L, Hart J, Perego C, et al: Pancreatic islet amyloidosis, beta-cell apoptosis, and alpha-cell proliferation are determinants of islet remodeling in type-2 diabetic baboons. Proc Natl Acad Sci USA 106: 13992-13997, 2009.

42. Andreone T, Meares GP, Hughes KJ, Hansen PA and Corbett JA: Cytokine-mediated $\beta$-cell damage in PARP-1-deficient islets. Am J Physiol Endocrinol Metab 303: E172-E179, 2012.

43. Muhd Radzi SF, Rückert C, Sam SS, Teoh BT, Jee PF, Phoon WH, Abubakar S and Zandi K: Detection of Langat virus by TaqMan real-time one-step qRT-PCR method. Sci Rep 5: 14007, 2015

44. Livak KJ and Schmittgen TD: Analysis of relative gene expression data using real-time quantitative PCR and the 2(-Delta Delta C(T)) method. Methods 25:402-408, 2001. 